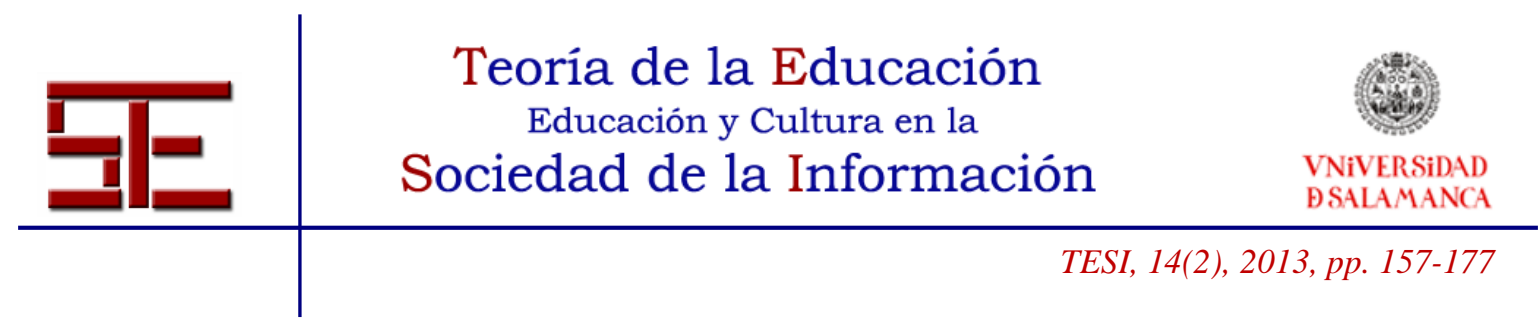

\title{
EL PORTAFOLIOS DIGITAL COMO HERRAMIENTA PARA EL DESARROLLO DE COMPETENCIAS TRANSVERSALES
}

Resumen: Partiendo de un enfoque sobre las relaciones entre las tecnologías digitales como herramientas de mediación, se analiza el papel de un caso concreto, los portafolios electrónicos, para la mejora de competencias transversales en el ámbito universitario. Los resultados indican que se obtienen mejoras, como mínimo desde la percepción de los propios estudiantes, en algunas dimensiones ligadas a la capacidad para seleccionar y organizar información, así como a la planificación del aprendizaje.

Palabras clave: Portafolios digitales; competencias transversales; aprendizaje; tecnologías para el aprendizaje.

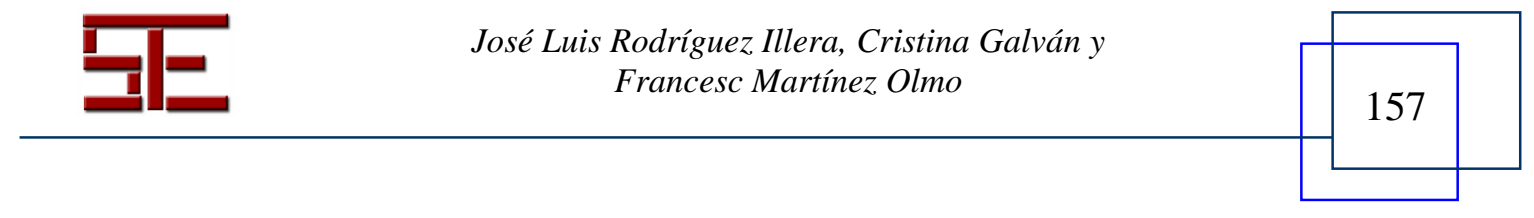




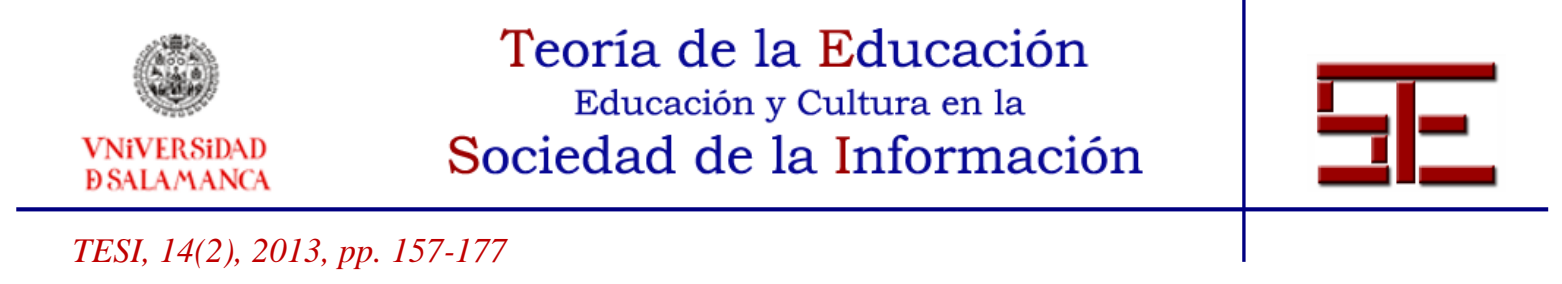
THE DIGITAL PORTFOLIO AS A TOOL FOR THE DEVELOPMENT OF
GENERIC SKILLS

\begin{abstract}
From an approach on the relationship between digital technologies as tools for mediation, we analyze the role of a specific case: electronic portfolios, to improve generic skills in the university environment. The results suggest that improvements are obtained, at least from the perception of the students themselves, in some dimensions related to the capacity to select and organize information, as well as learning planning.
\end{abstract}

Key words: Digital portfolios; generic skills; learning; technologies for learning.

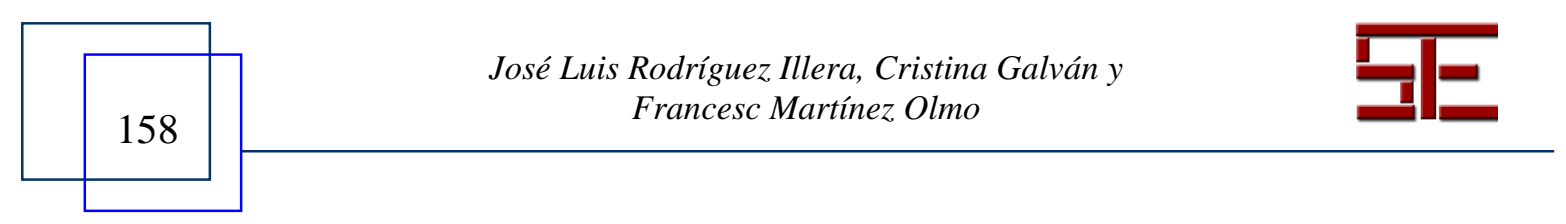




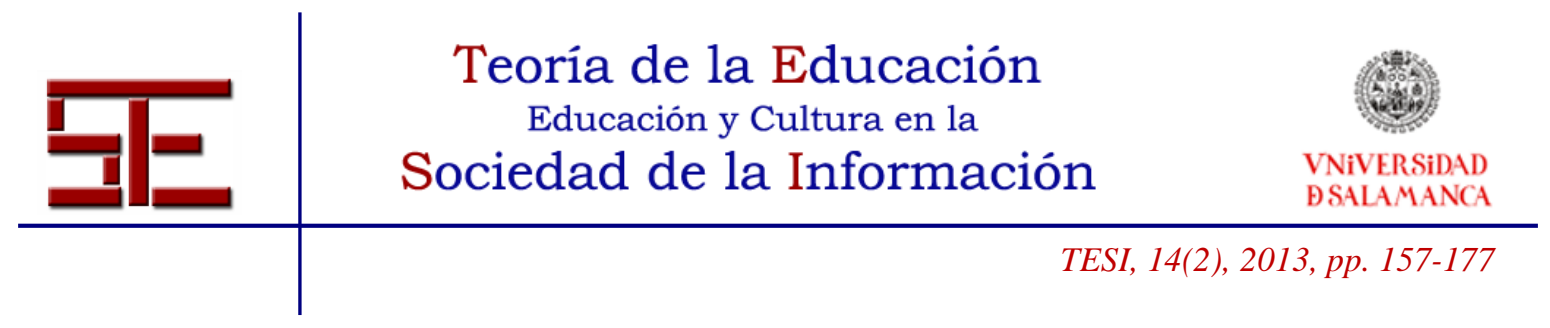

\section{EL PORTAFOLIOS DIGITAL COMO HERRAMIENTA PARA EL DESARROLLO DE COMPETENCIAS TRANSVERSALES}

Fecha de recepción: 20/04/2013; fecha de aceptación: 18/06/2013; fecha de publicación: 30/07/2013

José Luis Rodríguez Illera

jlrodriguez@ub.edu

Universidad de Barcelona

Cristina Galván Fernández

cgalvan@ub.edu

Universidad de Barcelona

Francesc Martínez Olmo

fmartinezo@ub.edu

Universidad de Barcelona

\section{1.- INTRODUCCIÓN}

En muchas ocasiones los denominados portafolios electrónicos o digitales han sido pensados como herramientas de evaluación educativa (Lankes, 1995; Zubizarreta, 2009; Cambridge, 2009; Stefani, Mason y Pegler, 2007; Barberà y Martín, 2009), especialmente como formas de evaluación alternativa (Meyer, 1992; Mateo y Martínez, 2008) y auténtica (Lidz, 1991; Meyer, 1992; Salvia y Ysseldyke, 2004; Cambridge, 2010). Sin duda, ése ha sido un aspecto muy importante en el momento de incluirlos en el conjunto de herramientas digitales que apoyan la docencia universitaria, hasta el punto de que son muchas las universidades que los utilizan, de manera muy variada, para estos fines evaluativos.

Junto a este uso "estandarizado" de los portafolios, vistos como una forma de asegurar una evaluación continuada y formativa, también son utilizados como ejemplos del propio proceso de aprendizaje, esto es, no sólo evidencias evaluativas o mostrativas de los aprendizajes realizados, sino como muestras de aquellos momentos en los que el estudiante ha mostrado una mejor o mayor comprensión o realización de unos objetivos o/y competencias.

Este carácter evaluativo y de aprendizaje, conjuntamente con los usos profesionales y realizativos, constituyen los principales activos de los portafolios universitarios y postuniversitarios. Sin embargo, hay otro enfoque que también puede considerarse en una

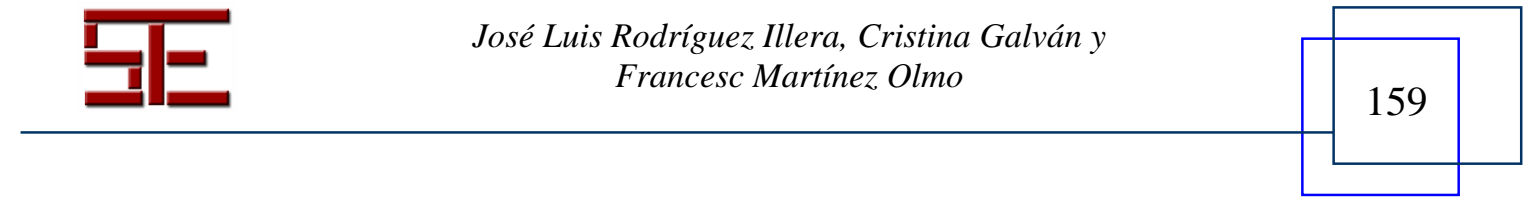




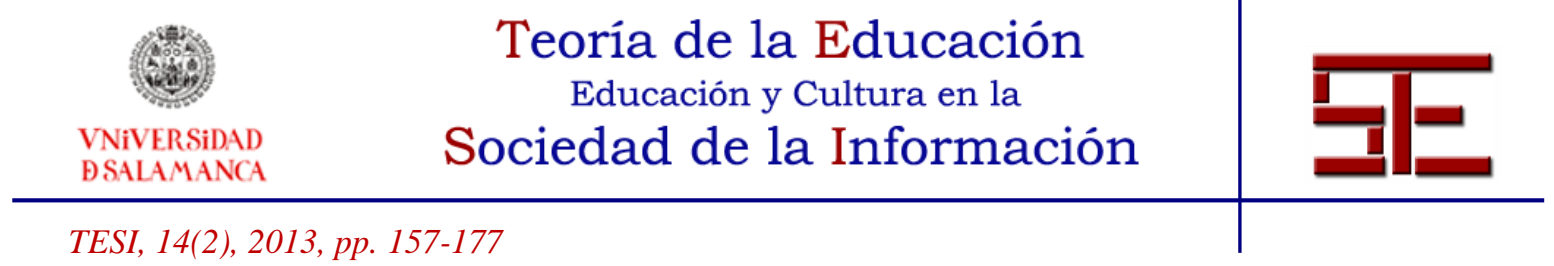

visión más amplia de los mismos. Si los usos anteriores son variantes de los portafolios considerados como herramientas al servicio de la relación educativa (evaluación, aprendizaje) o de la utilización comunicativa e informativa de su autor (profesionales, realización de logros, muestrario de habilidades y competencias para propósitos laborales), también se pueden considerar los portafolios como herramientas de mediación, que cambian a sus usuarios por el hecho de usarlas. Esta aproximación es legítima y de raíz vygotskiana, o postvygotskiana según se considere, y tiende a pensar que las denominadas "tecnologías de la información y de la comunicación" son, desde este punto de vista, herramientas simbólicas de mediación muy complejas.

Como ya se ha mantenido en otro lugar (Rodríguez Illera, 2004), las herramientas mediadoras no son tanto los ordenadores, o sus variantes tecnológicas, como las tabletas o los teléfonos inteligentes, sino su conjunción con las aplicaciones de software que aprovechan sus posibilidades y que permiten realizar acciones diferenciadas. En ese sentido, los portafolios en general y los portafolios digitales de manera más específica, constituyen una categoría de herramientas mediadoras, de carácter simbólico que operan sobre la información casi como extensiones de las operaciones cognitivas.

Hay varios enfoques para pensar qué supone el uso de estas herramientas, las ventajas e inconvenientes que conllevan, así como los cambios que se han producido en los últimos años por el uso continuado y constante de estos mediadores - sean portafolios, redes sociales o aplicaciones ya existentes, como procesadores de textos. Salomon y sus colegas (Salomon, Perkins y Globerson, 1992) mostraron una distinción que ha tenido gran influencia, al contraponer los efectos que produce el uso de la tecnología mientras se trabaja con ella, a los efectos más permanentes que acaba dejando en aquellos que la utilizan. Esta distinción entre efectos con y efectos de está basada en una oposición entre efectos efímeros y permanentes, o a corto y largo plazo. Los primeros son amplificadores de determinadas capacidades cognitivas, los segundos son modificadores de las mismas. Los primeros son fácilmente observables, por más que requieran un cierto cambio en la unidad de análisis que queremos observar al incluir una extensión tecnológica (Pea, 1993), mientras que los residuos cognitivos de los segundos se aprecian con mucha mayor dificultad. También Jonassen y Reeves (1996) han introducido el concepto de Mindtools para enfatizar cómo determinadas herramientas aportan funcionalidades específicas, en su mediación, que permiten una extensión de capacidades cognitivas concretas cuando son utilizadas (efecto con). Los portafolios digitales serían un ejemplo de este tipo de herramientas, por las funcionalidades que aportan en un entorno habitual de aprendizaje.

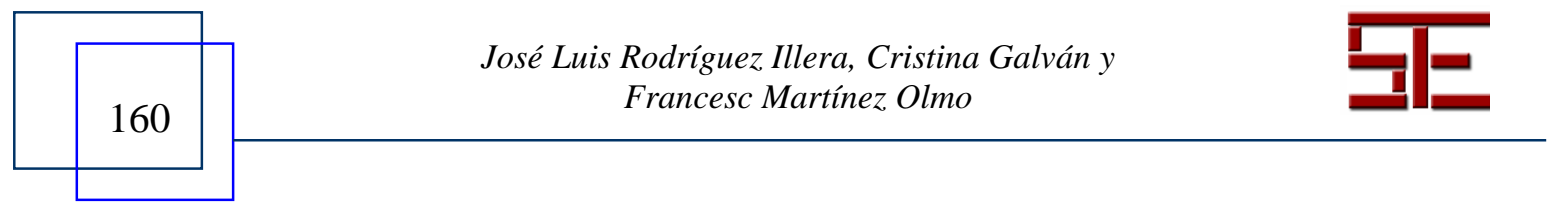




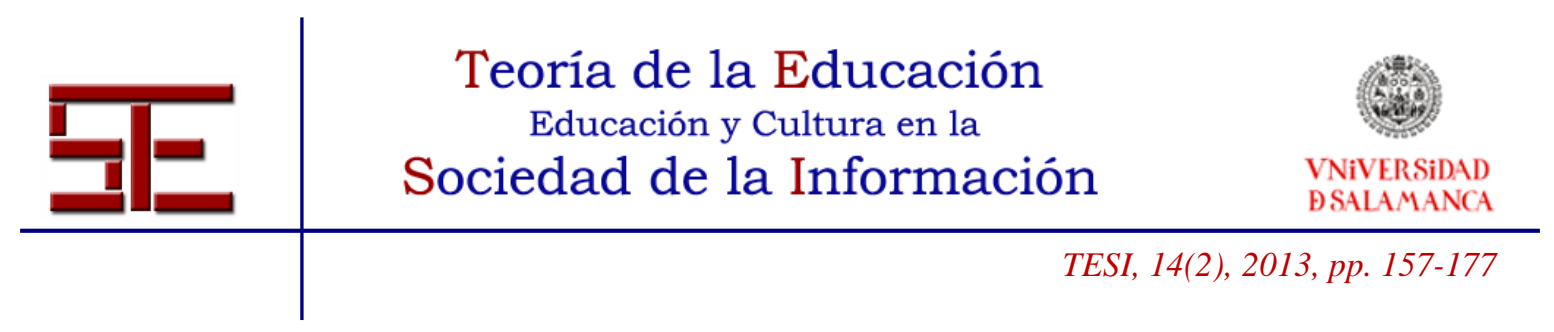

Ahora bien, hay algún aspecto a considerar en la distinción de Salomon. El principal, sin duda, es que se fundamenta en una dicotomía que hoy resulta menos evidente que hace años cuando fue enunciada. La diferencia entre el uso esporádico de una tecnología y su uso continuado parece estar basada, en gran medida, en la posibilidad de acceso a esa herramienta, aspecto que ha cambiado de manera evidente por la difusión generalizada de las mismas en nuestra sociedad actual. Las herramientas digitales han dejado de ser algo que se utilizaba cuando era posible acceder a un ordenador a algo que se ha convertido en cotidiano. Por tanto, las tecnologías digitales han pasado a convertirse en parte de nuestro entorno, casi omnipresentes, $y$, por tanto, integradas y no separadas de nuestra vida y de nuestros contextos y entornos de aprendizaje. De alguna manera, el corolario es que el eje de la frecuencia de uso (pensado como acceso) deja de ser tan central y el paso de los efectos con a los efectos de debería ser más un contínuum que una oposición tajante.

En segundo lugar, hay una cuestión referida al tipo de prácticas (o de usos, según otros autores) que las personas hacen con estas tecnologías. Aunque la distinción original está pensada para dar cuenta de las diferencias entre efectos de su uso sobre el aprendizaje, es decir, enfatizando la interacción de la persona con la tecnología, o con la aplicación informática, no podemos dejar de considerar el papel fundamental de guía que tienen los profesores, o simplemente de delimitar aquello que se pretende hacer con esa interacción persona-herramienta. Es decir, las interacciones están siempre en un contexto social o/y educativo que las encuadra, sean persona-herramienta o entre personas, en relación, si se quiere, a unos objetivos y contenidos curriculares.

Finalmente, la distinción siempre ha sido más indeterminada en relación a los efectos permanentes, los residuos cognitivos del uso continuado de las herramientas. Como es lógico, no es fácil definir en qué consisten, cuánto tiempo es necesario, cómo se miden, y una larga lista de problemas. Creemos que es así por el carácter heurístico de la distinción, quizá camuflado como si se tratase de una distinción sólo analítica, agravado por el crecimiento de esas interacciones y su omnipresencia cotidiana. ¿Cómo encontrar situaciones de uso y efectos sólo con? ¿Acaso no supone autolimitarnos en el tiempo y escala de observación? Claro que se pueden encontrar, acudiendo a grupos de control que no reciban el mismo tratamiento en el uso, aunque eso sea un poco artificial. También, desde luego, cuando la herramienta o su tratamiento didáctico constituyen una novedad y algunos estudiantes la desconocen. Pero la cuestión de delimitar los efectos a largo plazo sigue siendo compleja.

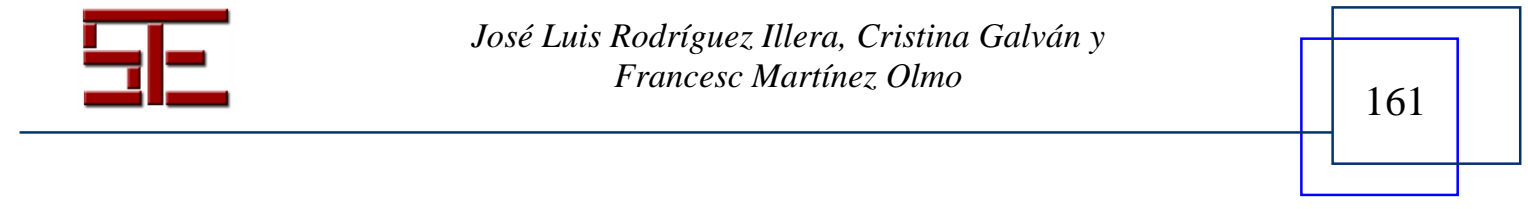




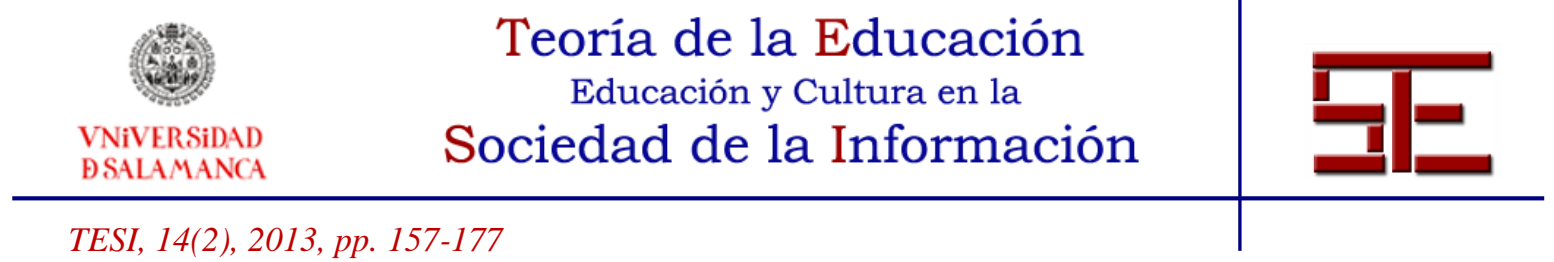

En el caso de los portafolios se agrava por el hecho de que muchas universidades (Jafari y Kaufman, 2006; Stefani, Mason y Pegler, 2007; Barberá, Gewerc y Rodríguez Illera, 2009) piensan en ellos como dispositivos para mostrar evidencias de aprendizaje y, sobre todo, mejoras competenciales. Si ya resulta complejo intentar siquiera comprender los efectos de que pueden proporcionar este tipo de herramientas, enunciarlos en términos de competencias se torna una tarea más difícil -en parte por la indefinición misma del concepto de competencia. A diferencia de esa concepción evaluadora, que los portafolios ayudarían a mostrar, nuestra intención es comprobar hasta qué punto ayudan a la mejora de algunas competencias (denominadas como "genéricas" o "transversales", Bennet, Dune y Carré, 1999; FEU, 1979; Hyland, 1993; Tribe, 1996 y González y Wagenaar, 2003), que parecen por un lado muy relacionadas con las tareas cognitivas que los portafolios enfatizan en contextos académicos, e intentar hacerlo, como mínimo, para los efectos con de Salomon.

\section{2.- COMPETENCIAS Y PORTAFOLIOS}

Las competencias genéricas son vistas por muchos autores (Bennett, Dunne y Carré, 1999; Tribe, 1996; Yániz y Villardón, 2006) como aquellas que se consideran útiles en distintos contextos académicos, laborales, sociales y personales a lo largo de la vida. Se trata, si se quiere por oposición con las competencias específicas o profesionales, de algo que responde a las necesidades de la vida cotidiana y de los ámbitos laborales en sentido amplio, en una sociedad cambiante tanto tecnológica como laboralmente, en la que las personas tienden a realizar varios tipos de trabajo a lo largo de sus años adultos. Las universidades europeas, en un proceso que tiene sus raíces en el denominado Espacio Europeo de Educación Superior, están incorporando estas competencias genéricas en sus planes de estudio, como auténticos objetivos de aprendizaje "competenciales", buscando la manera de evaluarlas y de determinar las que cada universidad considera básicas.

Barnett (2001) ha criticado el uso simplificado de la idea de competencia en la enseñanza superior, a la vez que ha realizado algunas propuestas centradas en analizar su desarrollo en la práctica docente y en los aprendizajes universitarios, más incluso que en la vida laboral. Aunque según este autor algunas de las competencias, y su desarrollo, estarían relacionadas con el capital cultural y habitus que los estudiantes ya poseen, no creemos que se pueda esquematizar su adquisición de esa manera -sobre todo porque el papel del sistema educativo, y especialmente en la enseñanza superior, es atenuar o incluso invertir el capital cultural familiar, y éste no puede considerarse como algo directamente predictivo en relación a los logros académicos y competenciales de los estudiantes

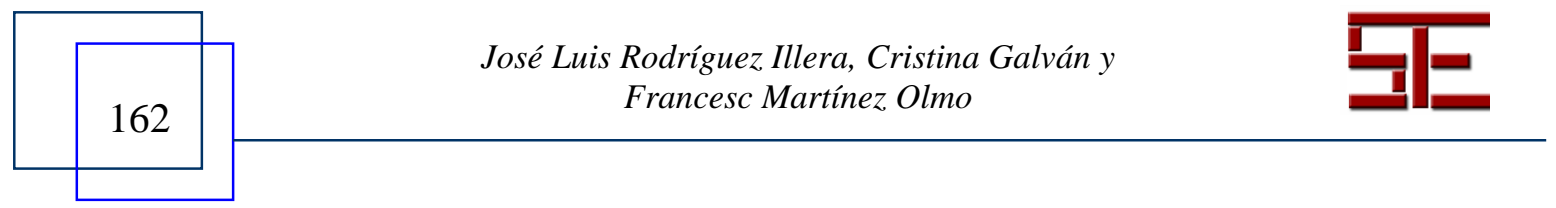




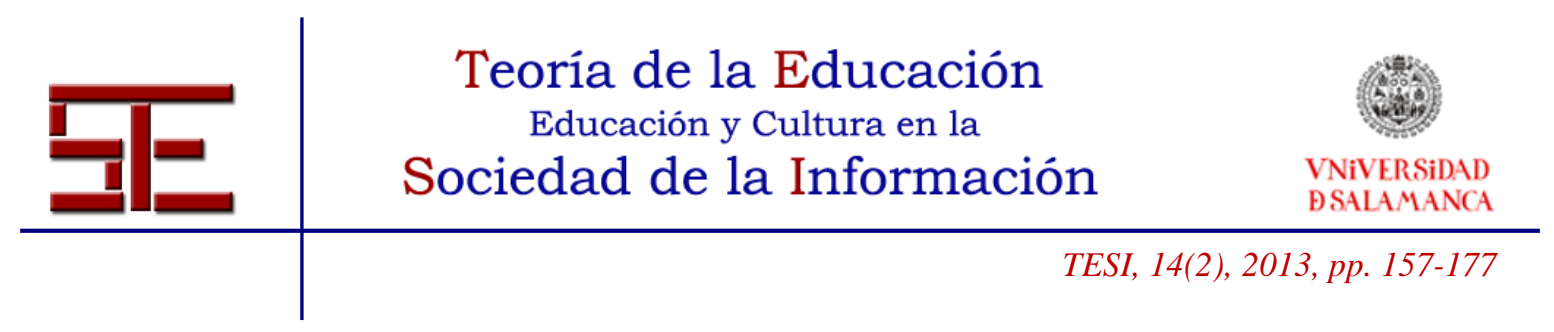

universitarios-. El propio Barnett ha señalado algunas estrategias para el desarrollo de competencias y mejora del aprendizaje universitario, tales como la reflexión sistemática sobre las propias acciones, o apoyarse en un diálogo en profundidad, o una evaluación continuada del propio aprendizaje. La mayoría de estas y otras propuestas coinciden con el enfoque mantenido sobre el uso de los portafolios como herramientas mediadoras para mejorar tanto la evaluación y el aprendizaje como la adquisición de competencias (Zubizarreta, 2009; Rodrigues, 2013; Rodríguez Illera, Rubio, Galván, Aguado y Quintana, 2011; Rodríguez Illera, 2009; Cambridge, 2010; Stefani, Mason, y Pegler, 2007).

En general, la idea de utilizar un sistema como los portafolios, que puede usarse para evaluación auténtica y que registra por tanto evidencias de tareas auténticas, supone un avance frente al uso de sistemas de evaluación convencionales en relación a las competencias, sean específicas o genéricas. Pero esto es así si existe una doble implicación, por parte de los profesores pero también de los estudiantes, dispuestos a un pacto de diálogo, es decir, a argumentar los aciertos y los posibles errores en la realización de las tareas (o, en el caso de las competencias, también en los "artefactos" aportados como realizaciones previas) basándose en las evidencias presentadas. Este enfoque supone un cambio muy importante en relación a formas de evaluación basadas únicamente en la realización de los estudiantes, y es el que está en la base de los portafolios aplicados tanto a la evaluación como al aprendizaje. Supone también un tipo de estudiante más comprometido con su propio aprendizaje (lo que Biggs ha denominado un "enfoque profundo", es decir, no sólo preocupado por aprobar el curso sino también por aprender y formarse).

Los portafolios ayudan a este estudiante activo, preocupado por su aprendizaje y capaz, en alguna medida, de regularlo. Le permite una representación de lo que está realizando durante el curso, lo que está comprendiendo y aprendiendo, y lo que es capaz de hacer, a través de las propias actividades del curso y de las reflexiones sobre el mismo. Los portafolios digitales especialmente ofrecen varios elementos de soporte para este proceso: a) la posibilidad de una evaluación "auténtica" y que integra lo que el estudiante decide mostrar (es decir, la evaluación no se limita a lo que el docente pregunta en formas de evaluación tradicionales como las pruebas); b) tener todo lo que ha realizado para la asignatura en un mismo lugar y disponible on-line; y c) aprovechar la multi-medialidad de los soportes digitales (grabaciones en vídeo, audio, esquemas, fotografías, textos,...) y del hipertexto para mostrar varios formatos de representación simbólica. Además, y dependiendo de las características de la plataforma que se utilice para generar el

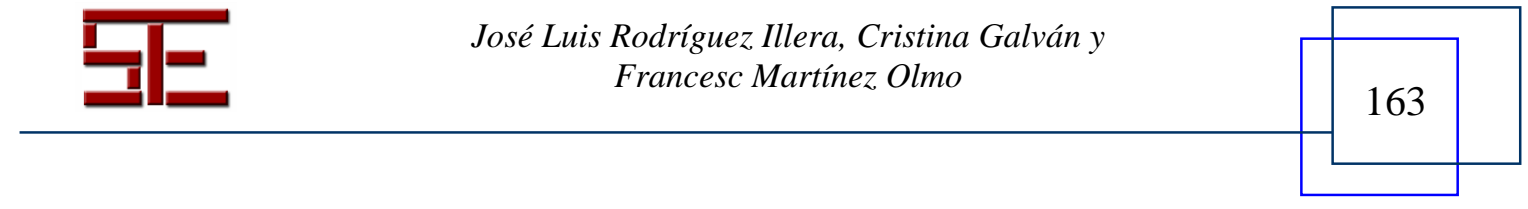




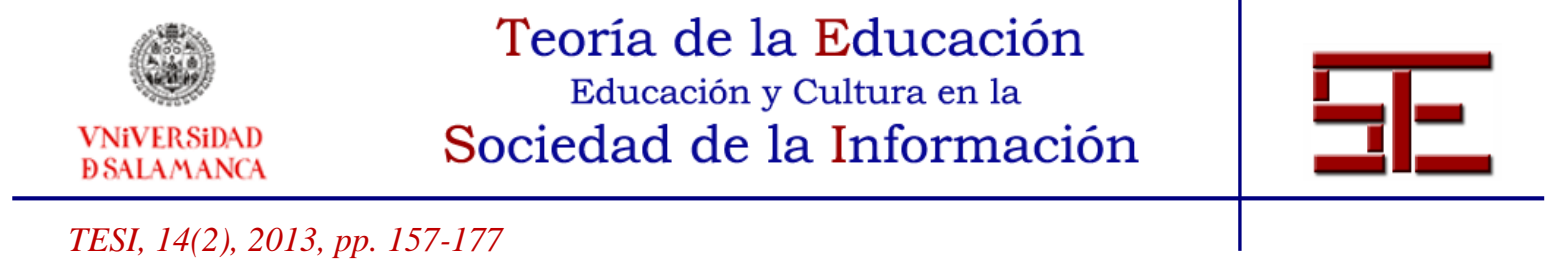

portafolios, el estudiante encuentra una ventaja adicional como es el disponer de un espacio personal, privado y permanente para ir desarrollando sus actividades y revisarlas cuando sea necesario. De nuevo, estas facilidades del portafolios (en el sentido de las affordances de Gibson [1979]) parecen estar muy unidas con los posibles efectos con de Salomon y sus colegas, en nuestro caso pensados como mejoras en determinadas competencias -por más que las competencias sean complejas de medir, más si cabe que son efectos "sólo cognitivos"-.

Por tanto, además de su utilización evaluativa, los portafolios digitales son diseñados para posibilitar y facilitar algunas acciones cognitivas que, con el uso continuado, se acaben transformando en disposiciones duraderas y competencias. Suponen un profesor y un estudiante ideal o modelo, dispuestos a implicarse en el proceso de aprendizaje y en el uso de la herramienta, en el marco de una situación de enseñanza-aprendizaje con una metodología didáctica determinada. $\mathrm{Y}$ aunque las competencias genéricas han sido sometidas a varias clasificaciones y puntos de vista (OCDE, 2005; Bennet, Dunne y Carré, 1999; Tait y Godfrey, 1999; Michavilla y Calvo, 1998; Prades, 2006), y se han enunciado múltiples, aquellas que creemos que están más relacionadas con el uso habitual de los portafolios son: a) selección y organización de la información; b) reflexión sobre el aprendizaje alcanzado y mostrado en las evidencias; y c) planificación del aprendizaje. Estas competencias, especialmente la primera y la última, se encuentran en la mayoría de las clasificaciones mencionadas ${ }^{1}$. Son, en gran manera, las que aparecen como un resultado del uso continuado de los portafolios y de sus efectos con a los que nos hemos referido.

\section{3.- OBJETIVOS Y METODOLOGÍA}

\footnotetext{
${ }^{1}$ En algunos casos las competencias forman parte de clasificaciones jerarquizadas. Así, la UNED al trazar su mapa de competencias genéricas establece subcategorías. La competencia "Planificación del aprendizaje" está definida en esta propuesta por primera área "Gestión autónoma y autorregulada del trabajo" que consiste en 3 grupos de competencias: (i) competencias de gestión y planificación, (ii) competencias cognitivas superiores y (iii) competencias de gestión de la calidad y la innovación. La competencia "Selección y organización de la información" se encuentra en la segunda área "Gestión de los procesos de comunicación e información", concretamente en el grupo "Competencias en el uso de las herramientas y recursos de la Sociedad del Conocimiento" que comprende las subcompetencias: manejo de las TIC, Competencia en la búsqueda de información relevante, Competencia en la gestión y organización de la información y Competencia en la recolección de datos, el manejo de bases de datos y su presentación.
}

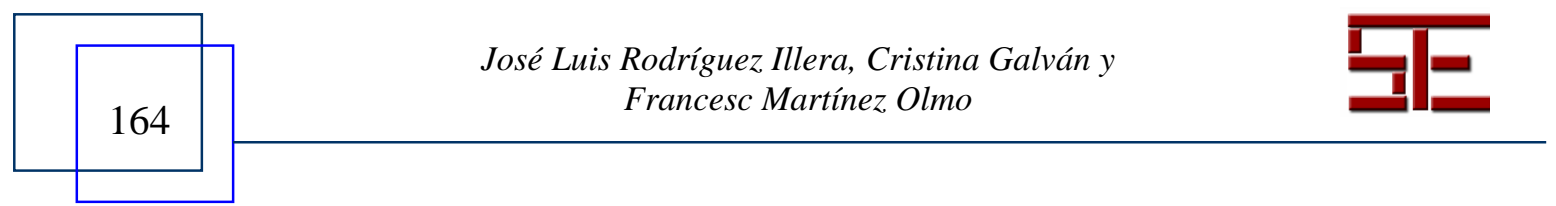




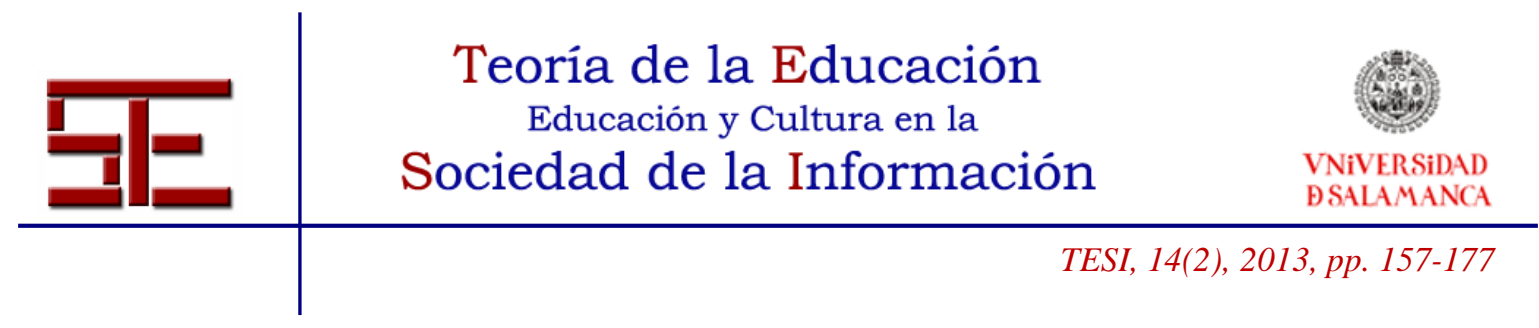

Este enfoque teórico nos ha permitido realizar un proyecto de investigación ${ }^{2}$ con el objetivo de comprobar algunos aspectos muy concretos, relativos a las competencias más implicadas en los efectos del uso de esta tecnología. Nos hemos centrado en el desarrollo de competencias relacionadas con las estrategias de aprendizaje: a) selección y organización de la información y b) planificación del aprendizaje. Otras competencias, como la capacidad reflexiva, han sido objeto de otras investigaciones paralelas (Rodrigues, 2013).

Dado que un marco teórico siempre puede concretarse en múltiples aproximaciones y diseños de investigaciones, hemos limitado la presente investigación a unos objetivos determinados (competencias transversales señaladas), y en especial a una metodología de tipo ex-post-facto y mixta a través de los siguientes instrumentos de recogida de información: observación de los portafolios digitales, cuestionarios Reviewed-Study Process Questionnaire-Two Factor y Assessment Experience Questionnaire a estudiantes y entrevistas en profundidad a profesores. Se han contestado los dos cuestionarios en dos momentos: antes de iniciar el tratamiento didáctico con portafolios digitales, y haciendo referencia a portafolios en papel o a examen, y una vez finalizado el tratamiento haciendo referencia al portafolios digital. Los resultados que se reportan se han analizado conjuntamente buscando cambios significativos en los ítems que corresponden a competencias transversales concretas.

Los participantes han sido estudiantes de las siguientes asignaturas:

\begin{tabular}{|l|l|l|}
\hline Curso & Titulación & Asignatura \\
\hline $2009-2010$ & $\begin{array}{l}\text { COMUNICACIÓN } \\
\text { AUDIOVISUAL }\end{array}$ & Investigación de Medios \\
\hline $2009-2010$ & PEDAGOGÍA & Pedagogía de la Formación a Distancia \\
\hline $2009-2010$ & PEDAGOGÍA & Pedagogía de la Comunicación \\
\hline $2010-2011$ & PEDAGOGÍA & Pedagogía de la Formación a Distancia \\
\hline $2010-2011$ & PEDAGOGÍA & Pedagogía de la Comunicación \\
\hline
\end{tabular}

\footnotetext{
${ }^{2}$ Evaluación del diseño y del uso de los portafolios electrónicos, en el contexto del EEES, como herramientas para la evaluación y el aprendizaje por competencias, financiada por el Ministerio de Ciencia e Innovación (2009-2012), y una variante posterior iniciada en 2013.
}

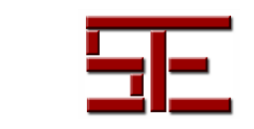

José Luis Rodríguez Illera, Cristina Galván y Francesc Martínez Olmo 


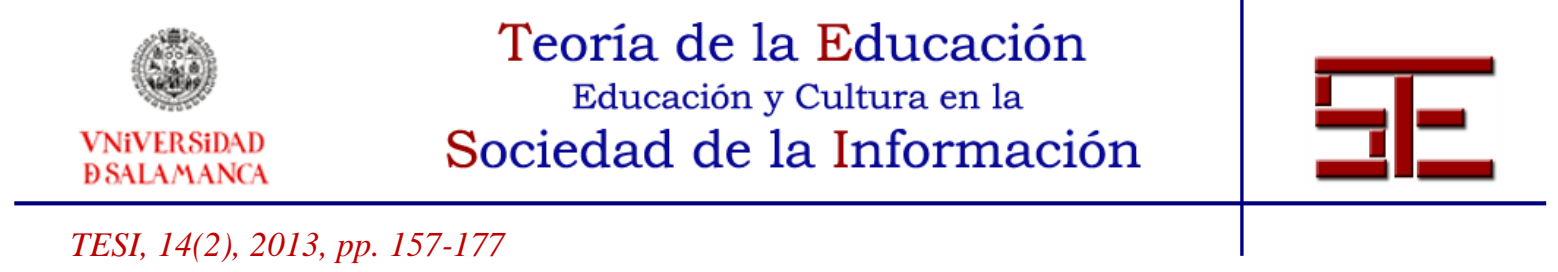

\begin{tabular}{|l|l|l|}
\hline 2011-2012 & PEDAGOGÍA & Pedagogía de la Formación a Distancia \\
\hline $2011-2012$ & PEDAGOGÍA & Pedagogía de la Comunicación \\
\hline $2011-2012$ & EDUCACIÓN SOCIAL & Usos, posibilidades y límites de las TIC \\
\hline
\end{tabular}

Tabla 1. Muestra seleccionada de portafolios digitales.

Los estudiantes de la muestra han contestado voluntariamente a los dos cuestionarios. En concreto 99 estudiantes han contestado el primer cuestionario y 88 el segundo. Para obtener información adicional se han analizado las narraciones de los estudiantes de la asignatura Pedagogía de la formación a distancia, un total de 61 estudiantes. A diferencia del resto de estudiantes han elaborado una reflexión acerca del uso del portafolios digital de manera voluntaria. La muestra también la componen cuatro docentes que han impartido las distintas asignaturas. El profesorado tenía experiencia previa con el uso de portafolios en papel y en digital desde el año 2007. En cambio, para los estudiantes era una novedad realizar un portafolios digital.

Todos han utilizado la plataforma Carpeta Digital. Se ha utilizado, por consenso, el mismo tratamiento didáctico para todas las asignaturas dejando al profesorado la opción de planificar su asignatura con las actividades que considere oportunas. El tratamiento didáctico consiste en:

- $\quad$ sesiones de formación acerca de la plataforma, del concepto de portafolios digital y de cómo elaborarlo en la asignatura;

- diálogo continuado entre docente y estudiante;

- realizar portafolios de proceso dando importancia a las reflexiones del estudiante.

En todos los casos, el portafolios digital recogía las actividades del curso y reflexiones y se elaboraba en las horas de trabajo autónomo del estudiante (horario no lectivo).

Las variables dependientes del estudio son dos competencias en concreto: planificación del aprendizaje y selección y organización de la información. Los instrumentos de evaluación se han analizado por separado. Para los cuestionarios, de carácter cuantitativo, se han utilizado las pautas recomendadas por los autores y para las narraciones, de carácter cualitativo, se realizado el análisis de contenido según Miles y Huberman

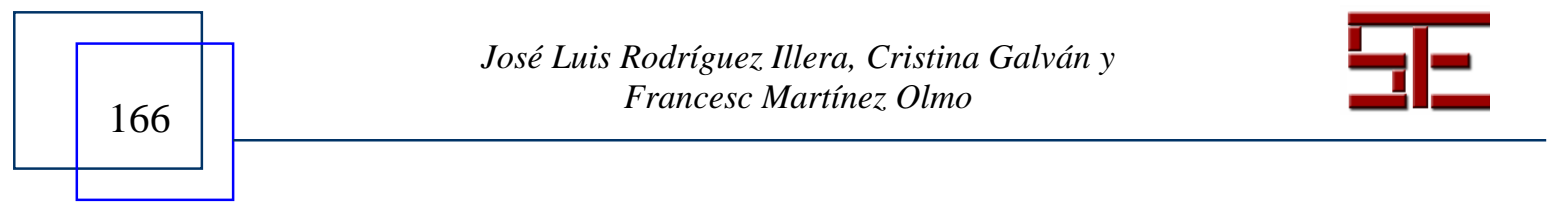




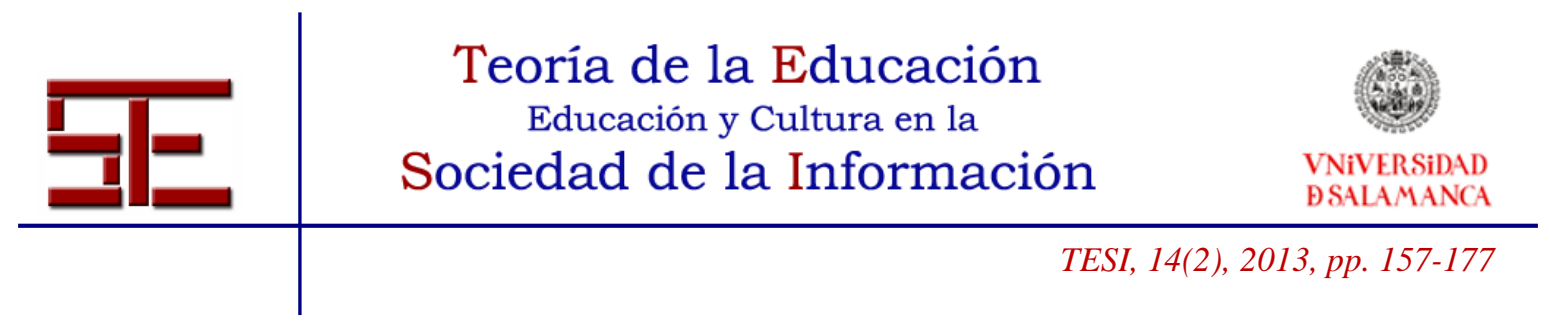

$(1994)^{3}$. El análisis de las competencias se ha hecho a través de los instrumentos mencionados. Tanto los datos cuantitativos como los cualitativos se han categorizado según pertenezcan a una u otra competencia. Las entrevistas en profundidad al profesorado se utilizan para confirmar el tratamiento didáctico utilizado y para conocer la percepción acerca del desarrollo de estas dos competencias en sus estudiantes.

\begin{tabular}{|l|l|l|}
\hline Competencia & $\begin{array}{l}\text { Cuestionario y } \\
\text { número de ítems }\end{array}$ & Características de los ítems relacionados con las competencia \\
\hline $\begin{array}{l}\text { Planificación del } \\
\text { aprendizaje }\end{array}$ & $\begin{array}{l}\text { AEQ: 16 } \\
\text { R-SPQ-2F: } 2\end{array}$ & $\begin{array}{l}\text { Esfuerzo; Dedicación extra; Interés; Tiempo dedicado; Métodos de } \\
\text { estudio; Revisión de la retro-alimentación }\end{array}$ \\
\hline $\begin{array}{l}\text { Selección y } \\
\text { organización de } \\
\text { la información }\end{array}$ & $\begin{array}{l}\text { AEQ: 3 } \\
\text { R-SPQ-2F: } 9\end{array}$ & $\begin{array}{l}\text { Desempeño; Información personal; Calificación; Satisfacción } \\
\text { personal; Calificación y esfuerzo; Contenido y evaluación; Interés y } \\
\text { dedicación extra; Interés del contenido. }\end{array}$ \\
\hline
\end{tabular}

Tabla 2. Categorización de los temas de ítems que corresponden a cada competencia.

La tabla de categorización de los datos cualitativos se ha elaborado a partir de las narraciones de los estudiantes acerca de su experiencia con los portafolios. En un primer momento se categorizaron los textos en dimensiones y aspectos y posteriormente se han clasificado las dimensiones y aspectos en las dos competencias que se analizan en el artículo.

\begin{tabular}{|l|l|l|}
\hline Tono expresivo $\left(1^{\mathrm{a}}\right.$ cifra $)$ & Dimensión $\left(2^{\mathrm{a}}\right.$ cifra $)$ & Aspecto concreto $\left(3^{\mathrm{a}}\right.$ cifra $)$ \\
\hline $1=$ positivo & Planificación & \\
\hline
\end{tabular}

\footnotetext{
${ }^{3}$ El tratamiento de los datos cuantitativos se ha realizado con el paquete estadístico SPSS v.20 y los cualitativos con el programa Atlas-Ti v.6.
}

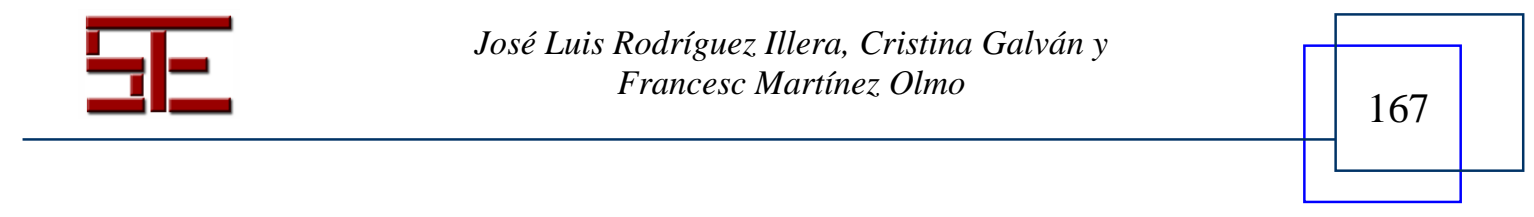




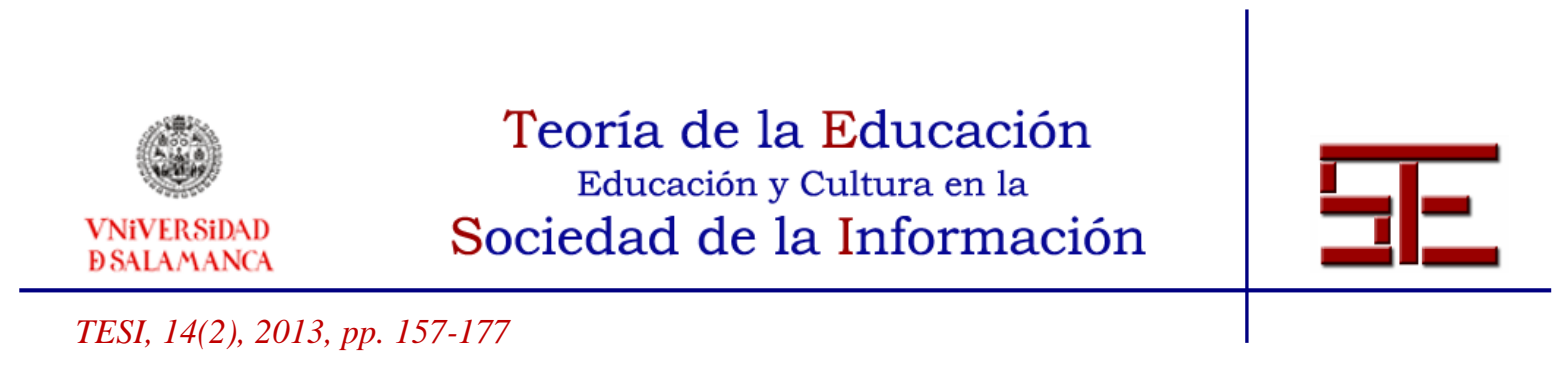

\begin{tabular}{|c|c|c|}
\hline \multirow{8}{*}{$\begin{array}{l}\begin{array}{l}3=\text { Aspectos positivos y } \\
\text { negativos }\end{array} \\
5=\text { Negativo } \\
7=\text { Ambiguo } \\
8 \quad=\text { Ninguno, no } \\
\text { identificable }\end{array}$} & 1=Elaboración & $\begin{array}{l}\text { 1=Tiempo } \\
2=\text { Facilidad } \\
\text { 4= Planificación } \\
5=\text { Progreso }\end{array}$ \\
\hline & $2=$ Aprendizaje & $\begin{array}{l}4=\text { Carencias } \\
5=\text { Progreso }\end{array}$ \\
\hline & $\begin{array}{ll}3= & \text { Proceso } \\
\text { Enseñanza/Aprendizaje } & \end{array}$ & $\begin{array}{l}2=\text { Seguimiento } \\
3=\text { Métodos de estudio } \\
\text { 4= Dificultad } \\
5=\text { Reflexionar } \\
6=\text { Evaluación }\end{array}$ \\
\hline & Selección y organización & \\
\hline & 1= Elaboración & $\begin{array}{l}3=\text { Organización } \\
6=\text { Edición } \\
7=\text { Colección }\end{array}$ \\
\hline & $2=$ Aprendizaje & $7=$ Relacionar \\
\hline & 4= Características & $\begin{array}{l}3=\text { Otros usos } \\
4=\text { Personalización }\end{array}$ \\
\hline & $5=$ Relaciones & $3=$ Contenido - Reflexión aprendizaje \\
\hline
\end{tabular}

Tabla 3. Tabla de codificación para el análisis de contenido de las narraciones sobre el uso del portafolios digital.

\section{4.- RESULTADOS}

\section{1.- Resultados de los cuestionarios}

El estudio muestra un análisis comparativo del estado de las competencias antes y después de realizar el portafolios desde la percepción de los estudiantes. Este análisis se ha

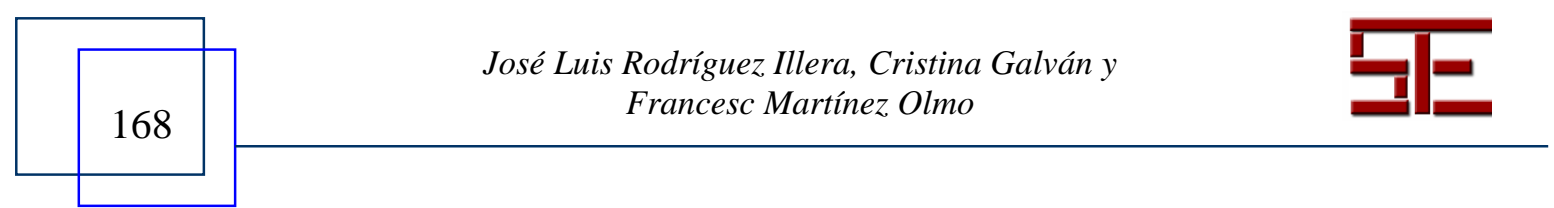




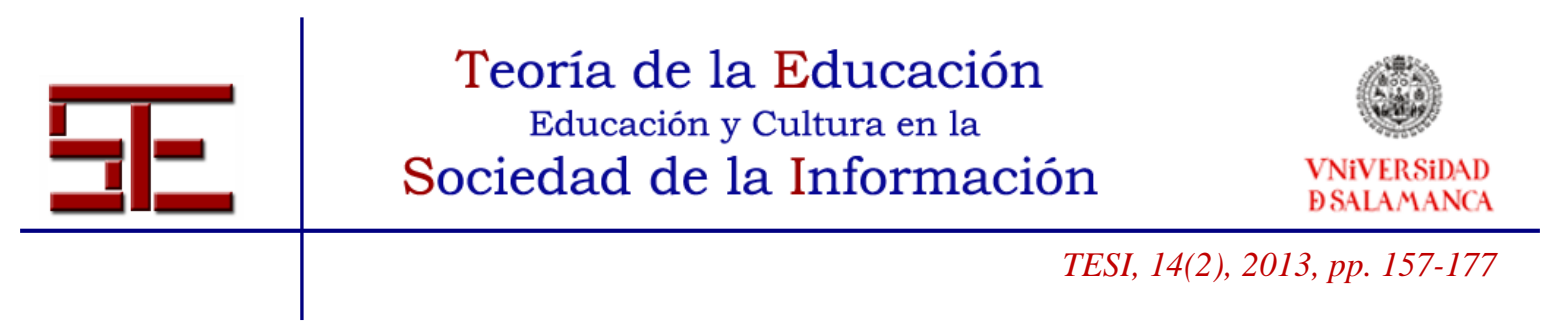

elaborado a partir de aplicar los cuestionarios (a) AEQ a 99 estudiantes voluntarios y (b) R-SPQ-2F a 88 estudiantes.

En ambos cuestionarios se ha aplicado la prueba de normalidad Shapiro-Wilk y dado que la mayoría de las variables no se ajustan a la normalidad se han analizado los resultados con pruebas de contraste de medias no paramétricas para conocer la significatividad del cambio de cada ítem entre el momento previo al tratamiento y el momento posterior. A continuación se muestran los resultados que han dado diferencias significativas entre ambos momentos y se especifican las medias (de una escala del 1 al 5) y la desviación típica.

\subsection{1.- Selección y organización de la información}

Cuando los estudiantes realizan el portafolios complementan información, buscan referencias para confirmar su opinión (media pre: 2,$78 ; S=0,890$ y media post: 3,$03 ; S=$ $0,915)$. Una buena selección de esta información mejora el contenido que será presentado posteriormente en la publicación del portafolios. Los portafolios digitales se caracterizan por promover la reflexión de los contenidos y del propio aprendizaje. En este sentido, parte de la información buscada corresponde a intereses personales del estudiante. En concordancia con el ítem "Considero interesantes la mayoría de temas nuevos y a menudo dedico tiempo extra para obtener más información sobre ellos", la elaboración del portafolios suscita explorar algunos contenidos con mayor interés (media pre: 2,$53 ; S=$ $0,909$ y media post: 2,$76 ; S=0,816)$. Las lecturas facilitadas durante el curso no se han percibido como una actividad central en las asignaturas (media pre: 3,56; $S=0,895$ y media post: 3,$32 ; S=0,989$ ) ni se han tenido en cuenta para la elaboración del portafolios. Habría que considerar el papel de las lecturas así como la relación que tenían con las actividades y con la elaboración del portafolios.

\subsection{2.- Planificación del proceso de aprendizaje y de elaboración del portafolios}

Los estudiantes revisan atentamente las retro-alimentaciones de las actividades anteriores como una estrategia para realizar las siguientes tareas y mejorar los aspectos necesarios. En general mantienen una regularidad en el trabajo del portafolios para llevar bien el curso (media pre: 3,$48 ; S=1,109$; media post $=3,2 ; S=1,072$ ) sin necesidad de emplear más horas en función de las tareas previstas (media pre $=2,49$, media post $=1,81$; $z=0,000)$. Las actividades planteadas para realizar el portafolios digital no han implicado mucho esfuerzo (media pre: 3,$25 ; S=1,090$; media post $=3,65 ; S=0,947$ ) para los

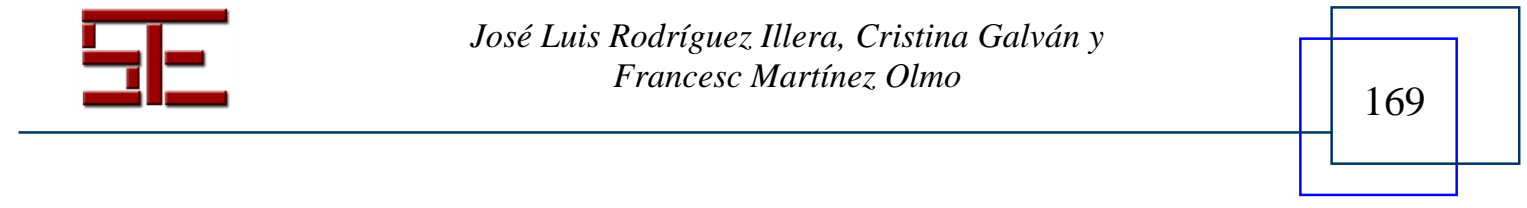




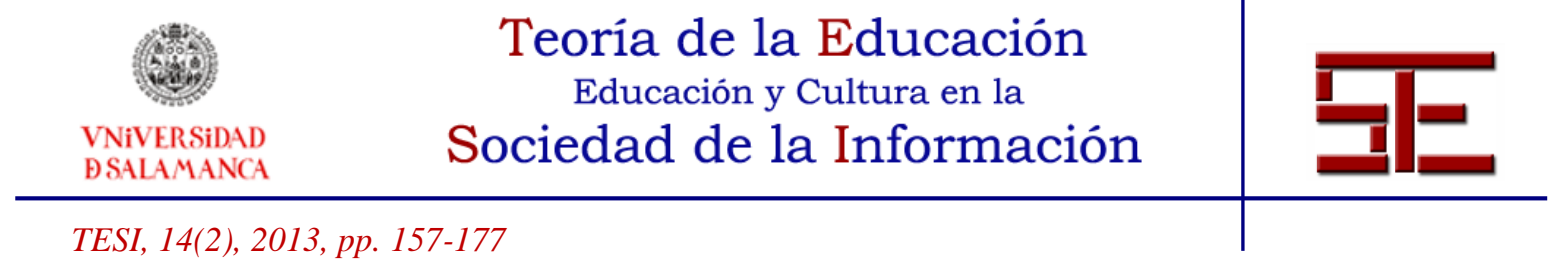

estudiantes. Una posible explicación es porque las actividades son comunes a otras asignaturas (mapas conceptuales, reflexiones, proyectos) y ya saben cómo realizarlas. No obstante, y según las entrevistas, lo que más cuesta son las reflexiones sobre el aprendizaje realizado. Por otra parte, al finalizar la asignatura dicen comprender mejor qué es y cómo hacer un portafolios digital. La retro-alimentación también tiene un papel importante para los estudiantes en el momento de planificar su aprendizaje. Si bien la retro-alimentación se tiene en cuenta para modificar una tarea, esta es medianamente transferible para la mayoría de estudiantes en la realización de posteriores actividades (media pre: 3,$51 ; S=1,451$; media post $=4,02 ; S=1,119$ ). Después de usar el portafolios digital los estudiantes dan más importancia a la retro-alimentación recibida (media pre: $3,57 ; S=1,314$; media post $=4,13 ; S=0,964)$.

Se puede observar, pues, cómo el uso de los portafolios digitales ofrece cambios significativos respecto a las experiencias previas de realización de examen o un portafolios en papel.

\section{2-. Resultados de las narraciones de los estudiantes}

Las narraciones de los estudiantes han abarcado temas de distinta índole: elaboración del portafolios, aprendizaje alcanzado, proceso de enseñanza-aprendizaje, características de la plataforma y relaciones establecidas. Estos temas han configurado la Tabla 3 [Tabla de codificación para el análisis de contenido de las narraciones sobre el uso del portafolios digital]. La codificación de las expresiones de los estudiantes ha permitido mostrar visualmente las percepciones de los estudiantes en cuanto al uso del portafolios digital para el desarrollo de las asignaturas.

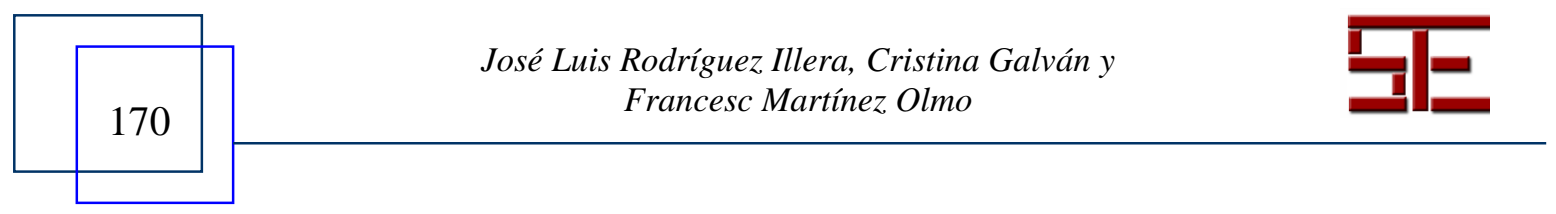



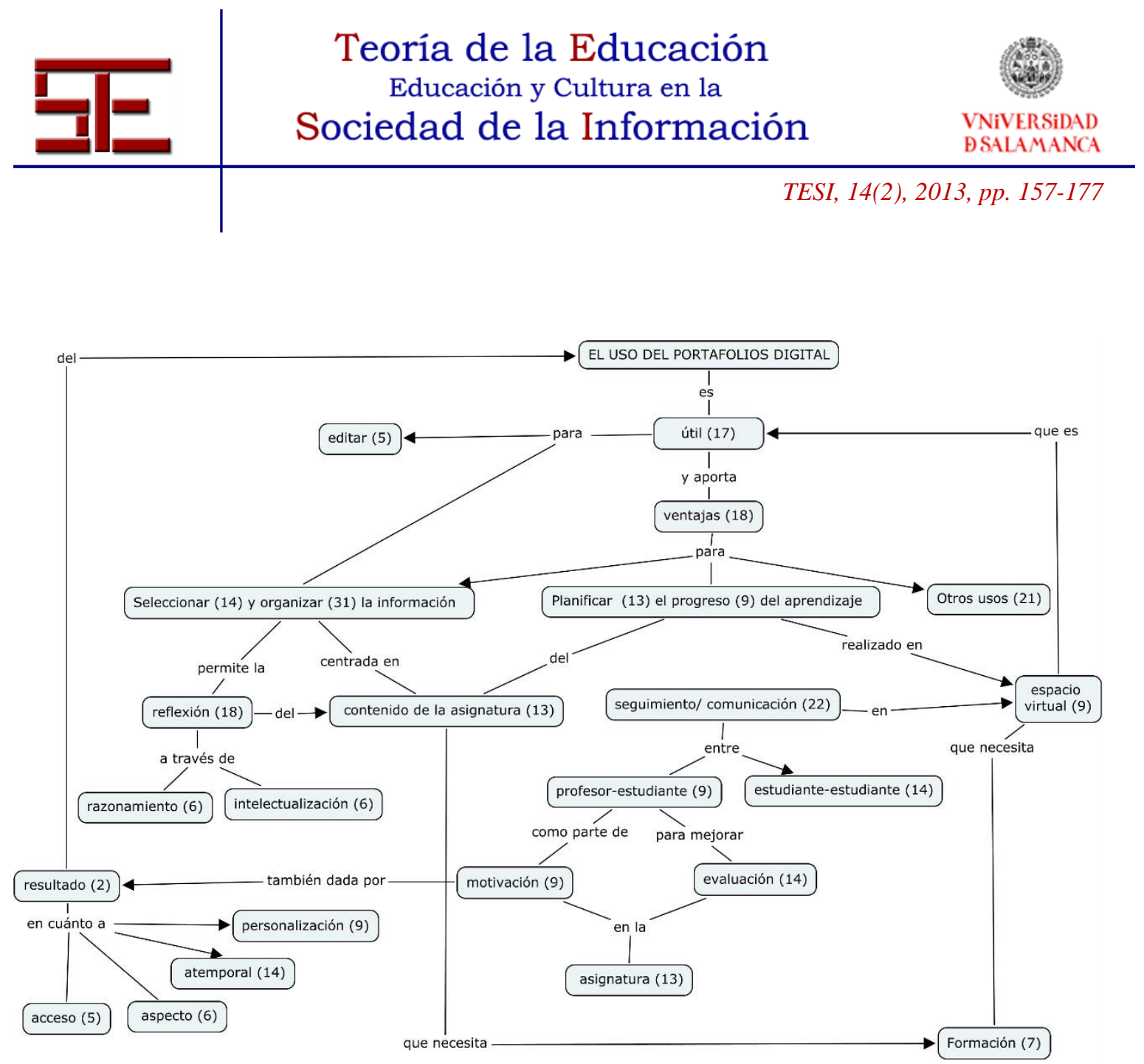

Ilustración 1. Esquema del discurso de los estudiantes sobre las competencias desarrolladas con el uso del portafolios digital. El valor (n) indica el número de citas expresadas por los estudiantes relacionadas con cada concepto.

En el esquema se observa como los estudiantes, de manera explícita o implícita, mencionan aquellos aspectos que valoran para realizar un portafolios digital: uso de un espacio virtual personal, tener una formación sobre la plataforma y cómo realizar un portafolios digital, comunicación con el profesor para realizar un seguimiento del progreso en la asignatura, reflexionar sobre el contenido y obtener un resultado digital personalizado y accesible (durante y después de la asignatura y desde cualquier lugar).

En cuanto a las dos competencias que se analizan se obtiene la siguiente información (se ha resaltado con el código $\{\mathrm{n}\}$ el número de citas relacionadas con cada concepto en las narraciones de los estudiantes):

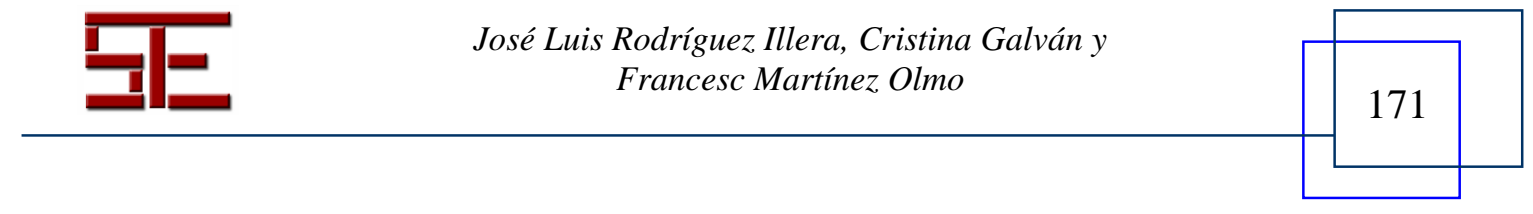




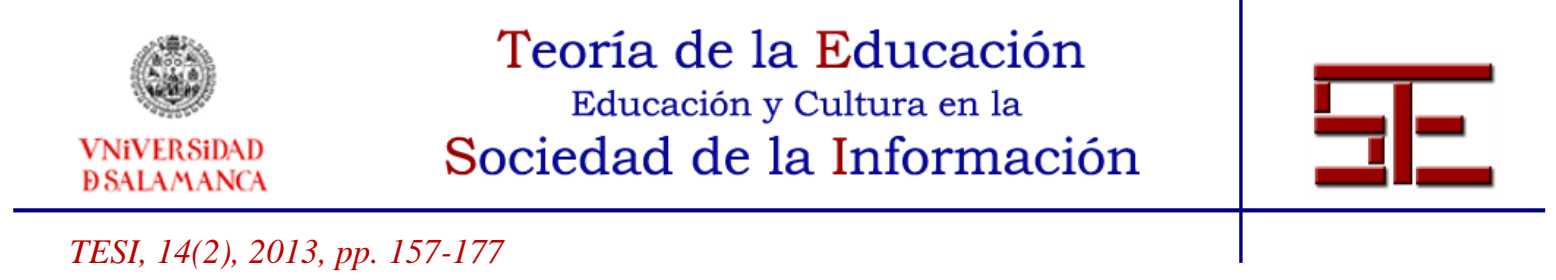

\subsection{1.- Selección y organización de la información}

La elaboración del portafolios conlleva seleccionar la información que se va a transmitir en el portafolios y mantener una organización de la misma. Esta organización incluye la de cada documento y la organización del portafolios en sí. En el caso de los portafolios realizados en Carpeta Digital la organización se visualiza a través de un menú desplegable.

El portafolios realizado ha sido de utilidad para los estudiantes $\{17\}$ y les ha ofrecido ventajas $\{18\}$ en el caso que han encontrado otros usos $\{21\}$ como tener el contenido de la asignatura bien organizado $\{31\}$. La evaluación como parte de la asignatura también ha tenido efecto en la selección de determinada información $\{14\}$.

\subsection{2.- Planificación del proceso de aprendizaje y de elaboración del portafolios}

El portafolios ha permitido realizar el seguimiento de los aprendizajes $\{22\}$ al estudiante manteniendo una buena comunicación entre el profesor y el estudiante $\{9\}$. También entre estudiantes se han ayudado para mejorar el portafolios digital $\{14\}$. Son trece estudiantes los que atribuyen una planificación del aprendizaje $\{13\}$ al seguimiento de los aprendizajes llevado a cabo con el profesor.

\section{5.- DISCUSIÓN Y CONCLUSIONES}

Los resultados nos muestran, en línea con investigaciones anteriores (López-Fernández y Rodríguez-Illera, 2009; Segers, Gijbels y Thurlings, 2010), que los estudiantes universitarios han mejorado ciertas competencias formativas una vez utilizado el portafolios digital: la gestión de las evidencias de aprendizaje de manera autónoma y la mejora del enfoque de aprendizaje. Las diferencias significativas entre algunas competencias, antes y después de realizar el portafolios, ayudan al estudiante a mantener un rol más activo en su proceso de enseñanza-aprendizaje, algo que también ha sido apoyado por dar más importancia a actividades que integran conocimientos, procedimientos y actitudes en vez de actividades más conceptuales (Barrett, 2001; Cambridge, 2010). Otro efecto también detectado ha sido la expansión de la búsqueda de información, más allá de la básica, sobre temas que les han resultado de interés, probablemente otro ejemplo de la autonomía que han tenido y de las formas de funcionamiento en la práctica de sus estrategias de mejora.

Algunos de los factores que favorecen estos resultados son variados, principalmente

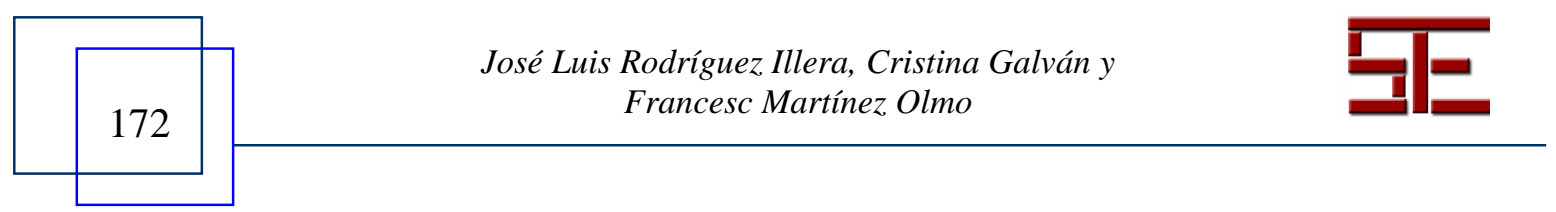




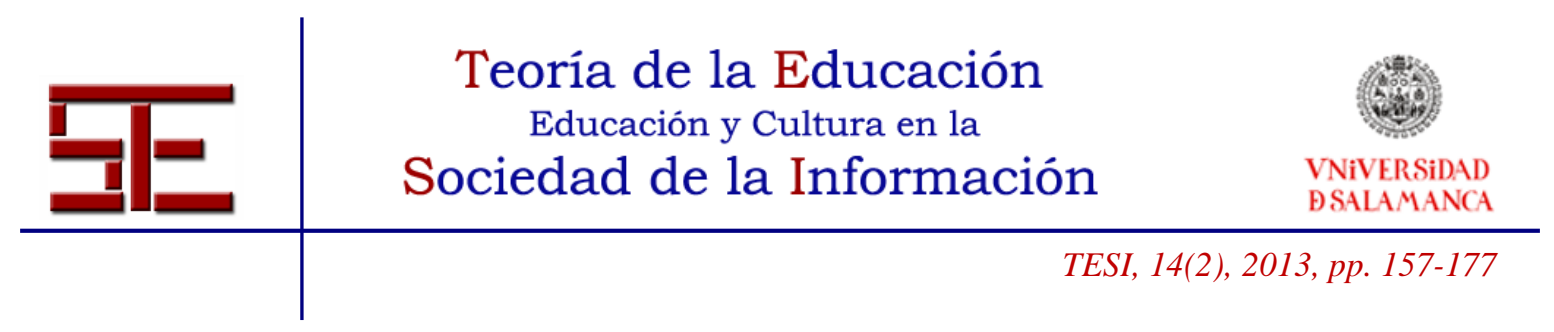

relacionados con la funcionalidad de diálogo $o^{4}$ que incorpora esta plataforma entre docente y estudiante: i) el hecho de recibir la retro-alimentación de los documentos de manera contextualizada en el interior de la plataforma, ii) recibir los mensajes en línea y disponer de ellos en cualquier momento y iii) poder mantener un diálogo con el docente de los documentos y del portafolios de carácter formativo y personalizado. Otros factores están relacionados con el tratamiento didáctico diseñado para potenciar los aprendizajes de los estudiantes y las competencias mencionadas, aprovechando las funcionalidades de los portafolios -si bien no era el objetivo de esta investigación y algunos de estos factores quedan indeterminados-.

La utilización de los portafolios digitales requiere componentes técnicos y pedagógicos: escoger una plataforma que tenga las funcionalidades que consideremos mejores o más adecuadas, mantener un diálogo activo, promover actividades de evaluación auténtica, entre otros. Al igual que con otras herramientas de mediación, los portafolios buscan un profesor y, sobre todo, un estudiante modelo, con carácter autónomo, capaz de gestionar y autorregular su aprendizaje en un contexto de evaluación académica. Sólo así la idea de los efectos con y de los efectos de alcanza todo su sentido, al igual que algunas de las distinciones de Biggs, en quien nos hemos basado. Por desgracia, estos estudiantes y profesores ideales no siempre se dan en la práctica; responden a un perfil que Cambridge (2010) ha denominado como de yo sinfónico, es decir, que busca una aproximación general al aprendizaje y la comunicación, intentando integrar la suma de sus experiencias y de sus ideas de manera coherente, en nuestro caso mediante el uso del portafolios. Este perfil no siempre se da, como decimos, sino que coexiste con otros enfoques hacia el aprendizaje, otra cultura escolar y personal, que hacen más complejo el propósito del portafolios como mediador.

Esta investigación, precisamente, abre algunos caminos a buscar nuevas funcionalidades y objetivos para el diseño de estas herramientas, con el objetivo de mejorar su impacto en los estudiantes y sus competencias. En primer lugar, sugiere un uso más continuado del sistema de portafolios como camino para incrementar los efectos cognitivos que ayuda a provocar. El uso continuado por parte del estudiante supone cambiar una dinámica que considera la herramienta como algo de utilización puntual - p. e. para cumplir los requerimientos del profesor-, y, por tanto, difumina la oposición de Salomon entre tipos

\footnotetext{
${ }^{4}$ Esta funcionalidad está basada en una adecuación al diseño de Carpeta Digital de una parte del concepto de zona de contacto (Pratt 1991), entendida sólo como zona de encuentro en Rodríguez Illera (2009).
}

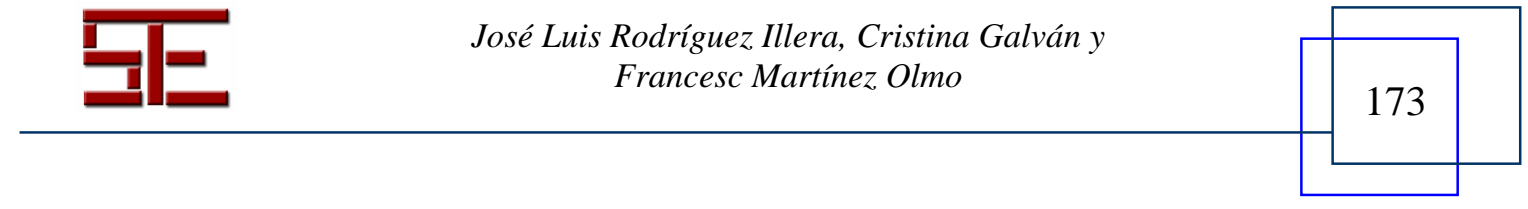




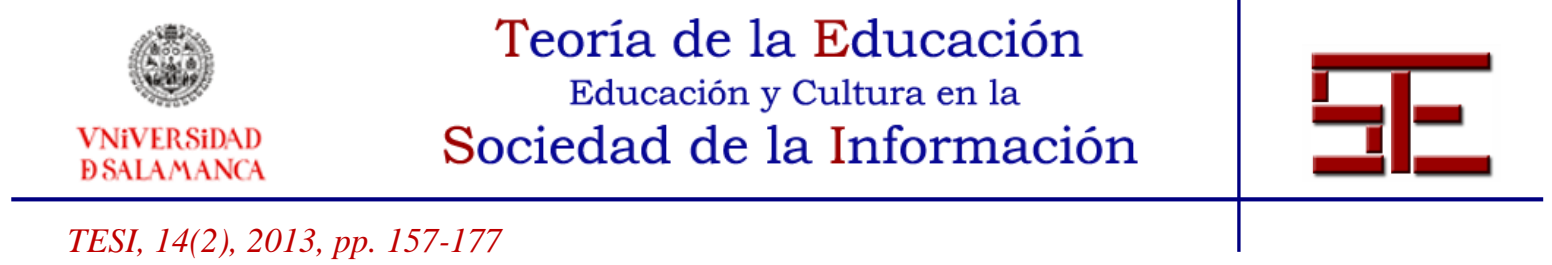

de efectos cognitivos y de aprendizaje. Para lograrlo, es necesario que el sistema aparezca como algo más integrado curricular e institucionalmente, y que así lo perciban los estudiantes y el profesorado.

Una posibilidad para lograrlo es mejorar la relación que debe mantener con el currículum institucional, sin dejar por ello la posibilidad de realizar portafolios personales. Incorporar aspectos centrales del currículum, tales como el plan docente de la asignatura, la asignación pautada de tareas, un calendario y un sistema de avisos por parte del profesor, así como de la coordinación tutorial, supondrá una integración mucho mayor con el punto de vista de los profesores y de la propia institución, a la vez que reforzará su conexión con el trabajo continuado de los estudiantes.

En segundo lugar, las formas de recepción y selección de la información que utilizan los estudiantes están muy unidas al uso de redes sociales, de enlaces y de RSS o suscripciones. Creemos que el sistema debe incorporar una fuente de información altamente personalizable para cada estudiante, así como de expresión mediante un editor incorporado, algo similar a lo que normalmente se denominan Entornos Personales de Aprendizaje (o PLE, por sus siglas en inglés), un concepto muy genérico y difuso pero que, en este caso, aparece de manera concreta en su integración con un sistema de portafolios ampliamente probado. Sin duda este tipo de nuevas funcionalidades van en la misma línea de mejorar del aprendizaje, y de las competencias, mediante el diseño de herramientas mediadoras cada vez más ajustadas.

\section{6.- BIBLIOGRAFÍA.}

Barberà , E. \& Martín, E. (2009). Portfolio Electrónico: aprender a evaluar el aprendizaje. Barcelona: Editorial UOC.

Barberà, E., Gewerc, A., y Rodríguez Illera, J. L. (2009). Portafolios electrónicos y educación superior en España: Situación y tendencias. Revista de Educación a Distancia, VIII (Portafolios electrónicos y educación superior), 13. Extraído el 1 de febrero, 2010, de http://www.um.es/ead/red/M8/intro.pdf.

Barnett, R. (2001). Los límites de la competencia. Barcelona: Gedisa.

Bennet, N.; Dunne, E. \& Carré, C. (1999). Patterns of core and generic skill provision in higher education. Higher Education, 37, 71-93.

Biggs, J., Kember, D. \& Leung, D. (2001). The revised two-factor Study Process Questionnaire: R-SPQ-2F. British Journal of Educational Psychology, 71, 133-149.

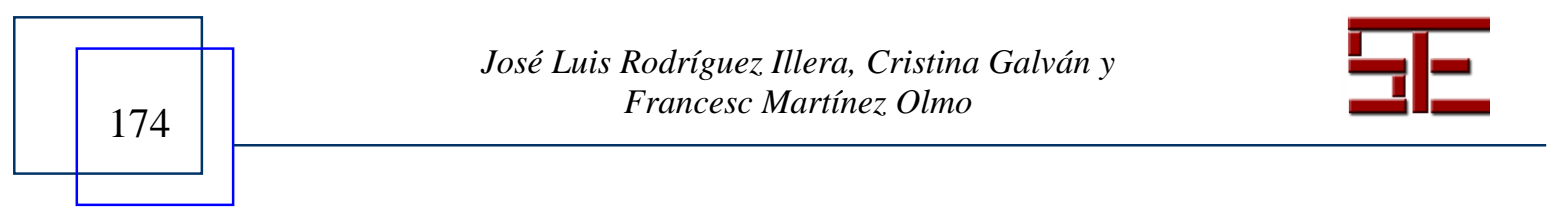




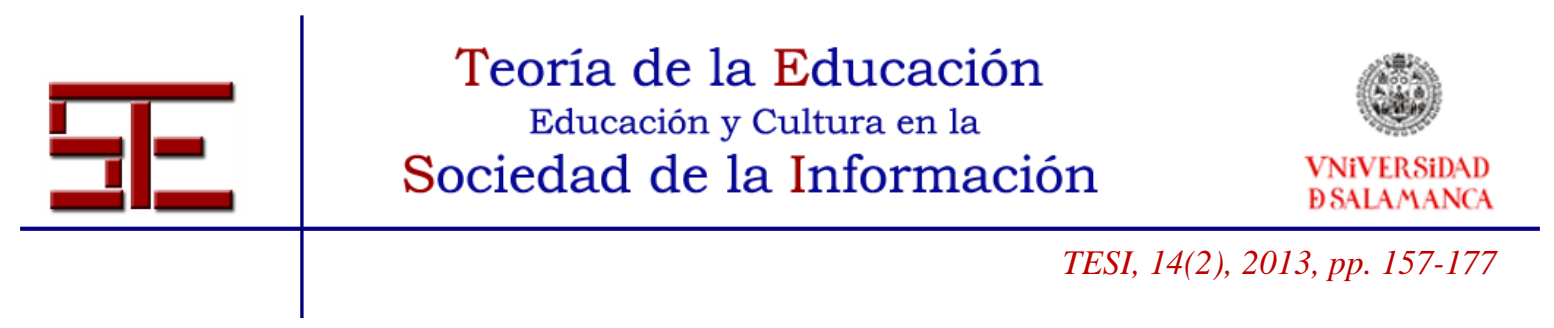

Cambridge, D. (2010). Eportfolios for Lifelong Learning and Assessment. San Francisco: Jossey-Bass.

Cambridge, D.; Cambridge, B. Y Yancey, K. (2009). Electronic Portfolios 2.0: Emergent Research on Implementation and Impact. Sterling, VA: Stylus Publishing.

FEU (1979). A Basis for Choice. London: FEU.

González, J. \& Wagenaar, R. (2003). Tuning Educational Structures in Europe. Deusto: Universidad de Deusto.

Hyland, T. (1993). Outcomes, Competence and NVQs in Higher Education: A Critique. Higher Education for Capability: NVQs and HE: opportunity or threat? Leeds. $\begin{array}{llllll}\text { Extraído el } & \text { el } & \text { de }\end{array}$ http://www.heacademy.ac.uk/assets/documents/resources/heca/heca_nv03.pdf.

Jafari, A. \& Kaufman, C. (2006). Handbook of Research on ePortfolios. Melbourne: Idea Group Reference.

Jonassen, D. H., \& Reeves, T. C. (1996). Learning with technology: Using computers as cognitive tools. En D. H. Jonassen (Ed.), Handbook of Research for Educational Communications and Technology (pp. 693-719). New York: Simon y Schuster.

Lankes, A. M. D. (1995). Electronic Portfolios: A New Idea in Assessment. ERIC Clearinghouse on Information and Technology Syracuse NY, 1-6. Extraído el 3 de noviembre, 2012, de http://www.users.muohio.edu/shermalw/electronicport_ed390377.pdf.

Lidz, C. (1991). Practitioner's Guide to Dynamic Assessment. New York: Guilford Press.

López-Fernandez, O. \& Rodríguez-Illera, J. L. (2009). Investigating university students' adaptation to a digital learner course portfolio. Computers y Education, 52 (3), 608616.

Mateo Andrés, J. \& Martínez Olmo, F. (2008). La evaluación alternativa de los aprendizajes. Cuadernos de Docencia Universitaria, 03. Barcelona: Octaedro-ICE UB. Extraído el 15 de junio, 2010, de http://www.octaedro.com/ice/pdf/DIG103.pdf.

Meyer, C. (1992). What's the difference between authentic and performance assessment? Education Leadership, 49 (8), 39-40.

Michavilla, F. \& Calvo, B. (1998). La universidad española hoy. Madrid: Editorial Síntesis.

Miles, M. B. \& Huberman, A. (1994). Qualitative data analysis: an expanded

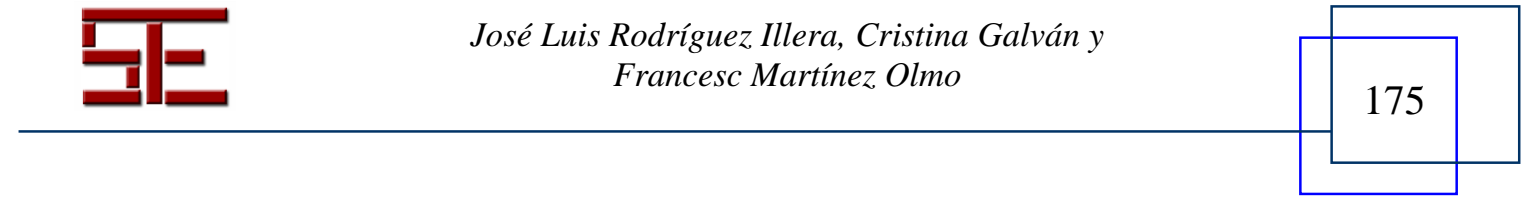




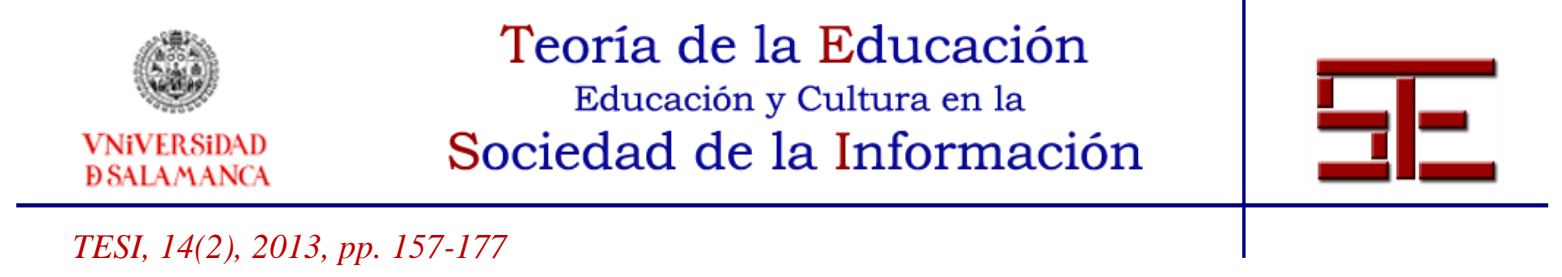

sourcebook. Newbury Park, CA: Sage.

OCDE (2005). La definición y selección de competencias clave: Resumen Ejecutivo. Extraído el 26 de febrero, 2009, de http://www.deseco.admin.ch/bfs/deseco/en/index/03/02.parsys.78532.downloadList .94248.DownloadFile.tmp/2005.dscexecutivesummary.sp.pdf.

Pea, R. D. (1993). Practices of distributed intelligence and designs for education. In G. Salomon (Ed.), Distributed cognitions: Psychological and educational considerations (pp. 47-87). New York: Cambridge University Press.

Prades, A. (2006). Les competències transversals i la formació universitària. Memoria para optar al título de Doctor. Mètodes d'Investigació i Diagnòstic en Educació, Universitat de Barcelona, Barcelona, España. Extraído el 8 de octubre, 2012, de http://www.tesisenxarxa.net/TESIS_UB/AVAILABLE/TDX-0404106-114952/.

Pratt, M. L. (1991). Arts of the Contact Zone. Profession. New York: Modern Language Association, 33-40.

Rodrigues, R. (2013). El desarrollo de la práctica reflexiva sobre el quehacer docente, apoyada en el uso de un portafolio digital, en el marco de un programa de formación para académicos de la Universidad Centroamericana de Nicaragua. Memoria para optar al título de Doctor. Teoria i Història de l'Educació, Universitat de Barcelona, Barcelona, España.

Rodríguez Illera, J. L. (2004). El aprendizaje virtual. Rosario: Homo Sapiens.

- (2009). Los portafolios digitales como herramientas de evaluación y de planificación personal. En M. Castelló (Comp.). La evaluación auténtica en Enseñanza Secundaria y universitaria: investigación e innovación (pp.145-163). Barcelona: Edebé.

Rodríguez Illera, J. L., Rubio, M. J., Galván, C., Aguado, G. \& Quintana, J. (2011). El uso de los portafolios electrónicos para mejorar la evaluación y el aprendizaje. En: A. Cornet, J. Pardo Carazo, \& T. Pagès Costas (Eds.). Buenas prácticas docentes en a universidad. Modelos y experiencias en la Universidad de Barcelona (pp. 143-152). Barcelona: Instituto de Ciencias de Educación de la Universitat de Barcelona.

Salomon, G., Perkins, D. N., \& Globerson, T. (1992). Coparticipando en el conocimiento: la ampliación de la inteligencia humana con las tecnologías inteligentes. Revista Comunicación, lenguaje y educación, 13, 6-22.

Salvia, J. \& Ysseldyke, J. E. (2004). Assessment in special and inclusive education (9th

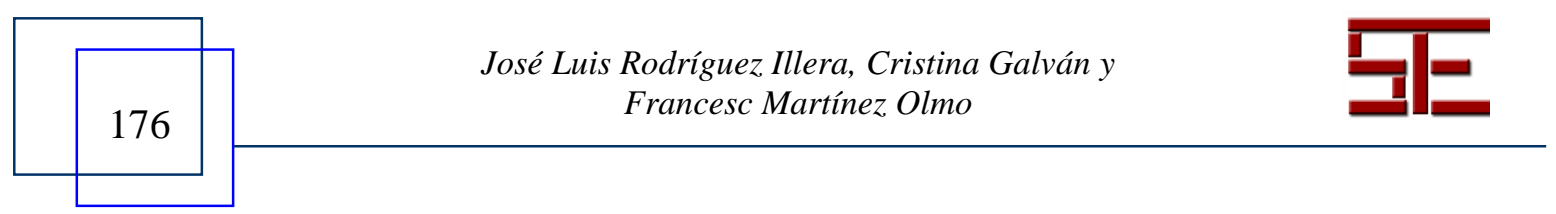




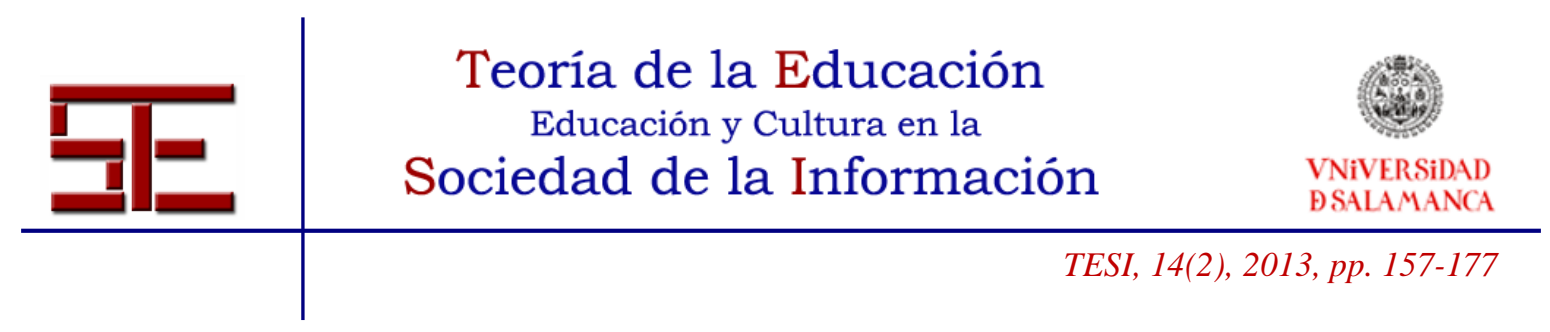

ed.). New York: Houghton Mifflin.

Segers, M., Gijbels, D. \& Thurlings, M. (2008). The relationship between students' perceptions of portfolio assessment practice and their approaches to learning. Educational Studies, 34 (1), 35-44.

Stefani, L., Mason, R. \& Pegler, C. (2007). The Educational Potential of e-portfolios: supporting personal development and reflective learning. Oxon: Routledge.

Tait, H. \& Godfrey, H. (1999). Defining and assessing competencies in Generic Skills. Quality in Higher Education, 5 (3), 245-253.

Tribe, J. (1996). Core skills: A critical examination. Educational Review. 48, 13-27.

Yániz, C. \& Villardón, L. (2006). Planificar desde competencias para promover el aprendizaje. Bilbao: Mensajero.

Zubizarreta, J. (2009). The learning portfolio. San Francisco: Anker.

Para citar el presente artículo puede utilizar la siguiente referencia:

Rodríguez Illera, J. L., Galván Fernández, C. y Martínez Olmo, F. (2013). El portafolios digital como herramienta para el desarrollo de competencias transversales en el alumnado. Revista Teoría de la Educación: Educación y Cultura en la Sociedad de la Información. 14(2), 157-177 [Fecha de consulta: dd/mm/aaaa].

http://campus.usal.es/ revistas_trabajo/index.php/revistatesi/article/view/10218/10627

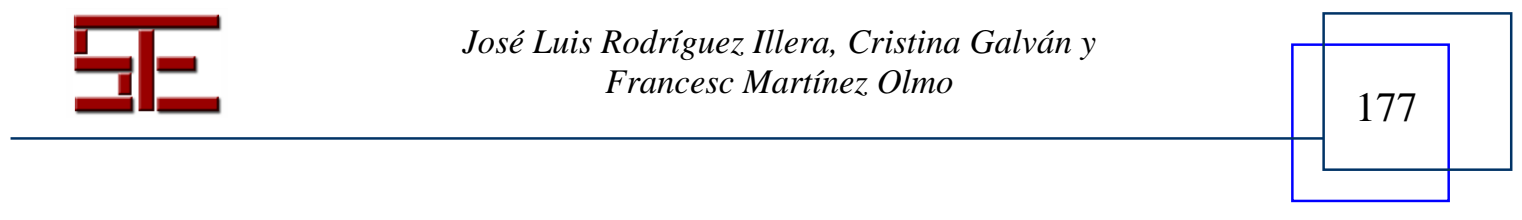

